\title{
Factors Affecting the Measurement of Energy Expenditure during Energy Balance Studies in Preterm Infants
}

\author{
JEFFREY PERRING, MARJORIE HENDERSON, AND RICHARD J. COOKE \\ Neonatal Intensive Care Unit, Directorate of Obstetrics, Gynaecology, and Neonatology, Royal Victoria \\ Infirmary, Newcastle Upon Tyne, United Kingdom NE1 4LP [J.P., M.H., R.J.C.]; and Department of \\ Child Health, University of Newcastle Upon Tyne, Newcastle Upon Tyne, United Kingdom NE1 4LP
}

[R.J.C.]

\section{ABSTRACT}

Our objective was to examine factors that affect the accuracy of energy expenditure measurements (EE), when using flowthrough indirect calorimetry (IC), to determine the minimum length of time needed to measure 24- and 48-h EE and to compare cross-over and parallel designs as methods of investigation during energy balance collections (EB) in preterm infants. A baby doll manikin was used to determine equilibration times and to compare $\mathrm{VCO}_{2}$ and $\mathrm{VO}_{2}$ as measured by flow meter and indirect calorimetry under different study conditions, one of which simulated an EB. "Continuous" EE was measured to determine the minimum length of time needed to accurately reflect 24- and 48-h EE and to compare parallel and cross-over studies as methods of study design in a group of "normal" enterally fed preterm infants. The mean $( \pm \mathrm{SD})$ errors between flow meter and indirect calorimetry determinations for $\mathrm{VCO}_{2}$ and $\mathrm{VO}_{2}$ were $-1.9 \pm 2.5$ and $-1.8 \pm 4.3 \%$ under conditions that simulated an EB. Cumulative 6-h EE accurately predicted 24and 48-h EE. Expressed in absolute terms (kcal/d), EE did not change on a day-to-day basis but did increase over the 2-wk study period. Expressed on body weight basis ( $\mathrm{kcal} / \mathrm{kg} / \mathrm{d}), \mathrm{EE}$ did not change on a day-to-day or week-to-week basis. The variance in $\mathrm{EE}$ due to biologic variability; i.e. the parallel design, was $\sim 6$ times greater than that due to age, weight, and weight gain; i.e. the cross-over design. Indirect calorimetry, therefore, accurately measures EE in conditions simulating an energy balance collection. Six-hour EE determinations are valid estimate of EE during a 48-h balance collection, while cross-over studies may be the preferred method of study design during short-term studies of EE in preterm infants. (Pediatr Res 48: 518-523, 2000)
EE, energy expenditure
EB, energy balance collection
EI, energy intake
IC, indirect calorimetry
VCO $\mathbf{F M} / \mathrm{VO}_{2} \mathbf{F M}, \mathrm{VCO}_{2} / \mathrm{VO}_{2}$ measured by flow meter
VCO $\mathbf{2} \mathbf{I C} / \mathrm{VO}_{2} \mathbf{I C}, \mathrm{VCO}_{2} / \mathrm{VO}_{2}$ measured by indirect
calorimetry

Abbreviations
Accurate measurement of energy expenditure has important implications in the determination of energy requirements in preterm infants. Previous studies examining EE using flowthrough indirect calorimetry (IC) have yielded variable results (1-11). The extent to which this reflects differences in methodology, biologic variability, and/or factors such as dietary intake, age, weight, weight gain, etc., is not entirely clear.

The accuracy of IC with open-canopy gas sampling has been questioned. Bauer et al. suggest that accuracy is reduced with open-canopy sampling and variable depending on body position (12). During IC infants are placed under a canopy, which is removed and replaced at regular intervals for normal infant

Received February 9, 1999; accepted February 15, 2000.

Correspondence: RJ Cooke MD FRCPI FAAP, Ward 35, Leaze's Wing, Royal Victoria Infirmary, Newcastle Upon Tyne, United Kingdom, NE1 4LP.

Funded by grants from Medical Research Council, London, United Kingdom and Wyeth Nutrition International, Philadelphia, U.S.A. care. However, equilibration times after replacement of the canopy also vary (5-30 $\mathrm{min})(13-15)$ and may further confound EE determination.

These findings have important implications for EE measurements during energy balance collections (EB). Infants are more easily nursed under a canopy, while body position may be changed many times over a 48-h collection period. Infants may also be placed on a balance collection mattress containing holes, which although used to ensure complete urine and stool collection may limit the accuracy of gas sampling. Studies suggest that 24-h EE can be estimated from a 6-h EE measurement $(14,16)$ but EE varies on a day-to-day basis $(9,17)$ and the extent to which a 6 -h EE reading can be extrapolated to a 48-h EB collection has not been determined.

The purpose of this study, therefore, was to 1) measure the accuracy of gas sampling with open canopy flow-through IC under conditions simulating an EB collection, 2) determine the 
length of time needed to obtain EE measurements referable to a 48-h collection period, 3) assess the relative effects of biologic variability, age, body weight, and weight gain on EE in a group of stable enterally fed preterm infants.

\section{METHODS}

In vitro. Assessment was performed using open canopy flow-through indirect calorimetry (DELTATRAC IIT, Datex Division Instrumentarium Corp., Helsinki, Finland) using the gas dilutional model described by Takala et al. $(18,19)$ and McLean and Tobin (20). A dilutional mixture of $25 \%$ carbon dioxide in nitrogen (Cryoservice Ltd, Worcester, United Kingdom) was infused into the canopy to mimic oxygen consumption and carbon dioxide production (equations 1 and 2). The rate of flow, $3.0 \mathrm{~L} / \mathrm{min}$, was controlled using a variable area glass tube flow meter (independently calibrated by Universal Calibration Laboratories Ltd, Romsay, Hants, United Kingdom).

$$
\begin{gathered}
\mathrm{VCO}_{2}=\mathrm{WCO}_{2} \\
\mathrm{VO}_{2}=\mathrm{FiO}_{2} /\left(1-\mathrm{FiO}_{2}\right) \times \mathrm{WN} 2
\end{gathered}
$$

where $\mathrm{VCO}_{2}=$ simulated $\mathrm{CO}_{2}$ production, $\mathrm{WCO}_{2}=$ infused $\mathrm{CO}_{2}, \mathrm{VO}_{2}=$ simulated $\mathrm{O}_{2}$ consumption, $\mathrm{FiO}_{2}=$ inspired oxygen concentration, and $\mathrm{WN} 2$ = infused nitrogen.

The calorimeter was set up and maintained according to the manufacturer's instructions. Internal sensor calibrations were performed before each study while barometric pressure was checked daily. The flow generator was calibrated at weekly intervals.

The manikin, a baby doll weighing $1.5 \mathrm{~kg}$, was placed under the canopy provided by the manufacturer for neonates on a conventional neonatal mattress, which was considered the "reference standard." An infant nasal cannula (Salters Labs, Arvin, CA, U.S.A.) was attached to the flow meter. The prongs of the nasal end of the cannula were removed. The cannula was placed on the doll so that the two nasal holes were in line with nares $\sim 2 \mathrm{~cm}$ below the nasal bridge and secured in place using adhesive tape.

A dilutional mixture of $25 \%$ carbon dioxide in nitrogen (Cryoservice Ltd, Worcester, United Kingdom) was then infused at flow rates equivalent to $20 \mathrm{~mL} / \mathrm{min}$ of carbon dioxide $\left(\mathrm{VCO}_{2} \mathrm{FM}\right)$ and $15.6 \mathrm{~mL} / \mathrm{min}$ of oxygen $\left(\mathrm{VO}_{2} \mathrm{FM}\right)$. Carbon dioxide $\left(\mathrm{VCO}_{2} \mathrm{IC}\right)$ and oxygen $\left(\mathrm{VO}_{2} \mathrm{IC}\right)$ were then sampled minute-by-minute for $30 \mathrm{~min}$. Ten measurements were taken.

This process was repeated with the manikin placed on a balance mattress. During metabolic collections in our unit a cotton sheet is placed over the lower abdomen of the infant for esthetic purposes. To simulate this the process was again repeated with manikin placed on the balance mattress with a cotton sheet placed over the plastic surround of the canopy and the lower abdomen of the manikin.

Equilibration times were determined as follows. Each 30min study period was split into two 15 -min blocks. The mean $\mathrm{VCO}_{2} \mathrm{IC}$ of the second 15 -min block was calculated. $\mathrm{VCO}_{2} \mathrm{IC}$ of the first 15-min period was then plotted against time using polynomial regression analysis. The time at which $\mathrm{VCO}_{2} \mathrm{IC}$ of the first period achieved $95 \%$ of the mean value of $\mathrm{VCO}_{2} \mathrm{IC}$ of the second period was considered the equilibration time.

To determine accuracy, the manikin was again placed on a standard mattress. Gas flow was varied from $6-26 \mathrm{~mL} / \mathrm{min}$ $\left(\mathrm{VCO}_{2} \mathrm{FM}\right)$ and $4-20 \mathrm{~mL} / \mathrm{min}\left(\mathrm{VO}_{2} \mathrm{FM}\right)$. After a 15 -min equilibration period $\mathrm{VCO}_{2} \mathrm{IC}$ and $\mathrm{VO}_{2} \mathrm{IC}$ were measured continuously for $60 \mathrm{~min}$. At each flow rate five measurements were taken. This process was repeated with the manikin placed on the balance mattress, without and then with the cotton sheet in place.

Accuracy was determined as follows. Flow-meter determined values $\left(\mathrm{VCO}_{2} \mathrm{FM}, \mathrm{VO}_{2} \mathrm{FM}\right)$ for the 60 -min study period were corrected for temperature and pressure and then compared with calorimetric $\mathrm{VCO}_{2} \mathrm{IC}$ and $\mathrm{VO}_{2} \mathrm{IC}$ using the equations below:

$$
\begin{aligned}
& \text { Relative Error } \mathrm{VCO}_{2}(\%)= \\
& \qquad\left(\mathrm{VCO}_{2} \mathrm{FM}-\mathrm{VCO}_{2} \mathrm{IC}\right) \times 100 / \mathrm{VCO}_{2} \mathrm{FM}
\end{aligned}
$$

Relative Error $\mathrm{VO}_{2}(\%)=$

$$
\left(\mathrm{VO}_{2} \mathrm{FM}-\mathrm{VO}_{2} \mathrm{IC}\right) \times 100 / \mathrm{VO}_{2} \mathrm{FM}
$$

In vivo. This study was approved by the local ethical committee and informed consent was obtained from the parent(s) or guardians. EE was measured in 11 clinically stable enterally fed preterm infants (birth weight $<1500 \mathrm{~g}$ and gestation $<32 \mathrm{wk}$ ) with no evidence of systemic disease; i.e. not receiving supplemental oxygen or medications, on two occasions 1 week apart. Infants were nursed in an incubator, servo-controlled to maintain a neutral thermal environment.

Twenty-four-hour care was provided by research nurses responsible only for the study infant. Infants were fed by orogastric tube either by continuous or bolus infusion. Bottles of ready-to-feed formula were weighed before and after each feeding; differences in weights were used to calculate energy intake. Bottles were fed to completion. Differences in weight between the full and empty bottles were used as a cross-check for the accuracy cumulative weights between each feedings.

Spillage was collected on preweighed diapers placed around the infant, differences in weights between the clean and "soiled" diapers were used to calculate losses. Volume of intake was calculated by dividing differences in weight by specific gravity of the formula. Energy intake was then calculated from the volume fed and energy content of the formula.

The canopy was placed over the infant's head with the cotton cloth placed over the plastic surround. Measurements were made over $48 \mathrm{~h}$ and broken into two 24 -h collections. "Continuous" measurements are not possible because the canopy must be removed for normal infant care at regular intervals. After placement of the canopy, an equilibration time of 8 min was allowed before measurements commenced.

Measurements were recorded at 1-min intervals and averaged for the first 15, 30, 60, and $90 \mathrm{~min}$, and for the 3, 4, 5, 6, 7 , and $8 \mathrm{~h}$. Averaged values were then compared with the mean value of the 24-h reading. A cumulative collection period of $\geq 12 \mathrm{~h}$ was considered acceptable for a given 24 -h period. 


\section{Data Analysis}

Data analysis was performed using paired $t$ tests, standard Student $t$ test, regression analysis, and analysis of variance. Results were considered significant at $p<0.05$. In the case of multiple comparisons the Bonferroni-Dunn correction was applied.

A comparison of variance due to biologic variability, as occurs during parallel studies, and dietary intake, body weight, weight gain, age, etc., as occurs during cross-over, was done using the method described by Snedecor and Cochrane with Fisher's adjustment for degrees of freedom (21) and was as follows. The variance of all $\mathrm{EE}$ determinations was first determined (222P). For each infant the paired difference in EE between the 1st and 2 nd week was calculated. The variance of the mean paired difference for all infants was calculated $(\partial 2 \mathrm{C})$. Fisher's rule was then used to adjust both variances for differences in degrees of freedom. Differences in sample size requirements were then determined from the formula: $\mathrm{Np}=$ $2 \partial 2 \mathrm{P} \times \mathrm{Nc} / \partial 2 \mathrm{C}$, where $\mathrm{Np}=$ number of pairs required for parallel study and $\mathrm{Nc}=$ number of infant pairs used in cross-over.

\section{RESULTS}

In vitro. Thirty equilibration measurements were made. The results are presented in Fig. 1. Equilibration times for $\mathrm{VCO}_{2} \mathrm{IC}$ varied from 6-7 min and did not differ when the manikin was placed on the standard mattress, the balance mattress, and the balance mattress with the cotton sheet. Equilibration times for $\mathrm{VO}_{2} \mathrm{IC}$ also varied from 6-7 min and did not differ between the groups.
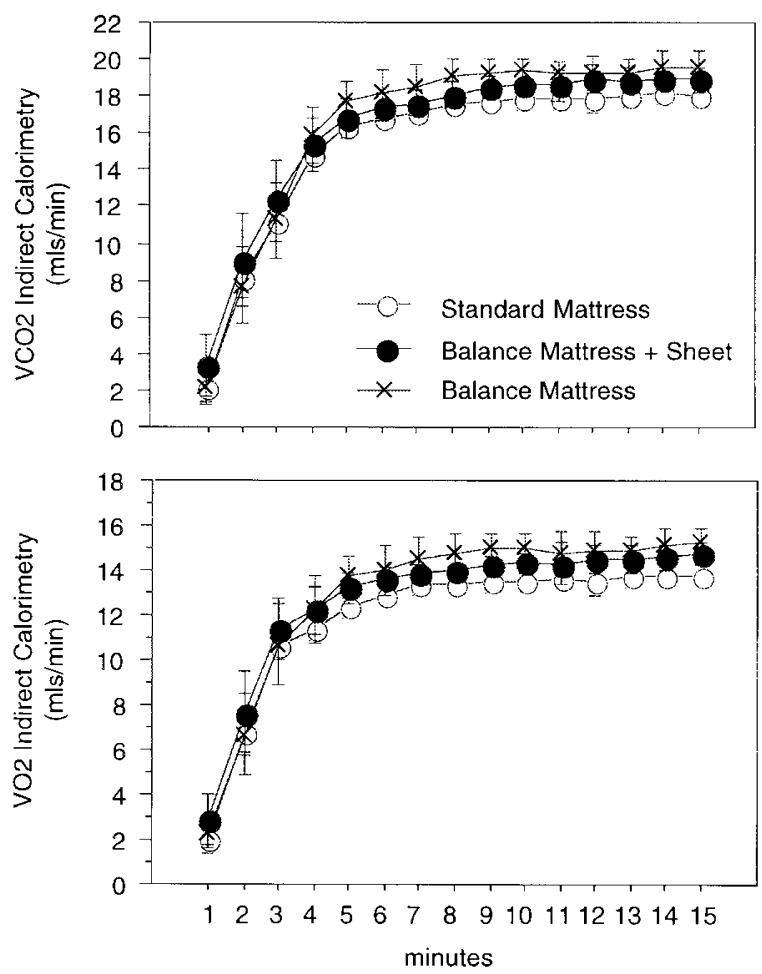

Figure 1. $\mathrm{VCO}_{2}$ and $\mathrm{VO}_{2}$ equilibration times.
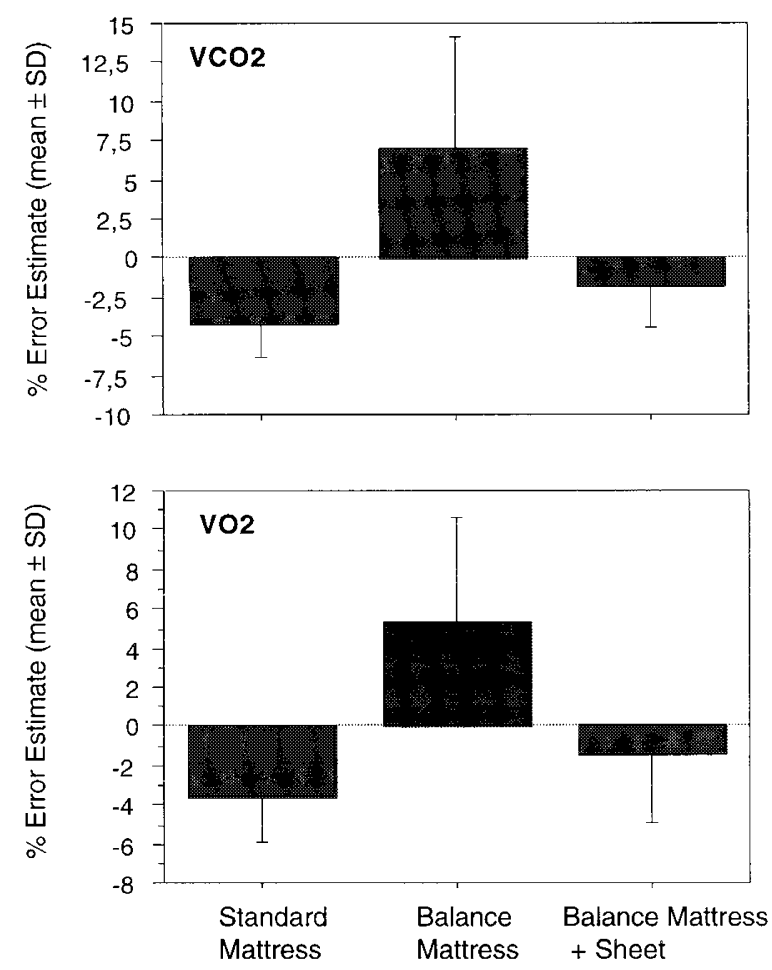

Figure 2. Error estimates for $\mathrm{VCO}_{2}$ and $\mathrm{VO}_{2}$ determinations.

One hundred forty-four accuracy determinations were made. No overall difference was noted between $\mathrm{VCO}_{2} \mathrm{IC}$ and $\mathrm{VCO}_{2} \mathrm{FM}(15.9 \pm 5.4$ vs $15.8 \pm 5.2 \mathrm{~mL} / \mathrm{min})$. However, the error varied and was least $(p<0.0001 ;$ Fig. 2$)$ with the balance mattress and the cotton sheet in place $(-0.3 \pm 0.4 \mathrm{~mL} / \mathrm{min}$; $-1.9 \pm 2.5 \%)$ compared with the standard mattress $(-0.7 \pm$ $0.4 \mathrm{~mL} / \mathrm{min} ;-4.3 \pm 3.1 \%)$ and the balance mattress alone $(1.2 \pm 1.4 \mathrm{~mL} / \mathrm{min} ; 7.0 \pm 7.1 \%) p<0.0001$; Fig. 2).

An overall difference of $0.17 \pm 0.9 \mathrm{~mL} / \mathrm{min}$, was noted between $\mathrm{VO}_{2} \mathrm{IC}$ and $\mathrm{VO}_{2} \mathrm{FM}(p<0.05)$. The error varied and was least ( $p<0.0001$; Fig. 2$)$ with the balance mattress and the cotton sheet $(-0.3 \pm 0.5 \mathrm{~mL} / \mathrm{min} ;-1.8 \pm 4.3 \%)$ when compared with standard mattress $(-0.6 \pm 0.5 \mathrm{~mL} / \mathrm{min}$; $-4.5 \pm 3.0 \%)$ and the balance mattress alone $(0.9 \pm 1.0$ $\mathrm{mL} / \mathrm{min}, 6.7 \pm 6.5 \%$ ).

The relationship between $\mathrm{VCO}_{2} \mathrm{IC}$ and $\mathrm{VCO}_{2} \mathrm{FM}$ and between $\mathrm{VO}_{2} \mathrm{IC}$ and $\mathrm{VO}_{2} \mathrm{FM}$ for the manikin placed on the balance mattress with the cotton sheet in place are presented in Fig. 3. For $\mathrm{VCO}_{2} \mathrm{IC}$ and $\mathrm{VCO}_{2} \mathrm{FM}$, the intercept was not different from zero and a direct linear relationship was seen between the variables $\left(\mathrm{r}^{2}=1.0 ; p<0.0001\right)$. For $\mathrm{VO}_{2} \mathrm{IC}$ and $\mathrm{VO}_{2} \mathrm{FM}$, the intercept differed from zero $(p<0.01)$ but a direct linear relationship was noted between the variables $\left(\mathrm{r}^{2}=0.99\right.$; $p<0.0001$ ).

In vivo. Forty-eight-hour EE determinations $(n=22)$ were performed on 11 preterm infants with a mean $( \pm \mathrm{SD})$ gestation $29.8 \pm 1.5 \mathrm{wk}$ and a birth weight $1.35 \pm 0.22 \mathrm{~kg}$ (mean $\pm \mathrm{SD})$. Mean $( \pm \mathrm{SD})$ weight and post- conceptional age during the 1st and 2 nd weeks of the study were $1737 \pm 267$ and $2125 \pm$ $355 \mathrm{~g}$ and $233 \pm 10$ and $241 \pm 10 \mathrm{~d}$, respectively. None of the infants received respiratory support or medications during the study. 

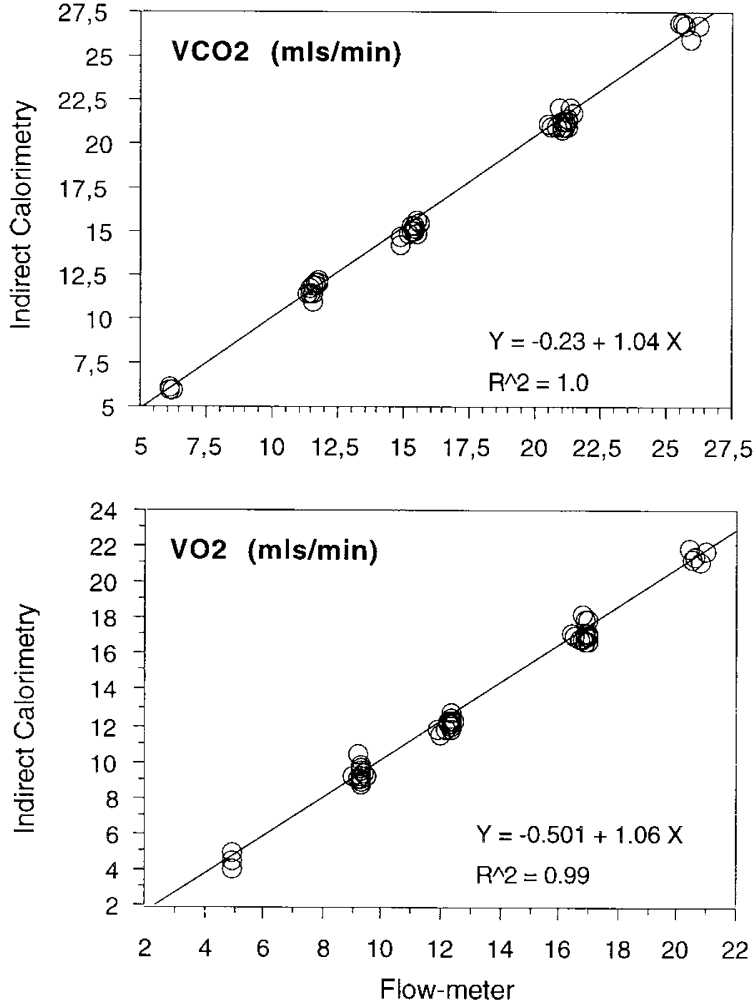

Figure 3. Relationship between $\mathrm{VCO}_{2} \mathrm{IC}$ and $\mathrm{VCO}_{2} \mathrm{FM}$ and between $\mathrm{VO}_{2} \mathrm{IC}$ and $\mathrm{VO}_{2} \mathrm{FM}$ with the manikin on the balance mattress and the cotton sheet in place.
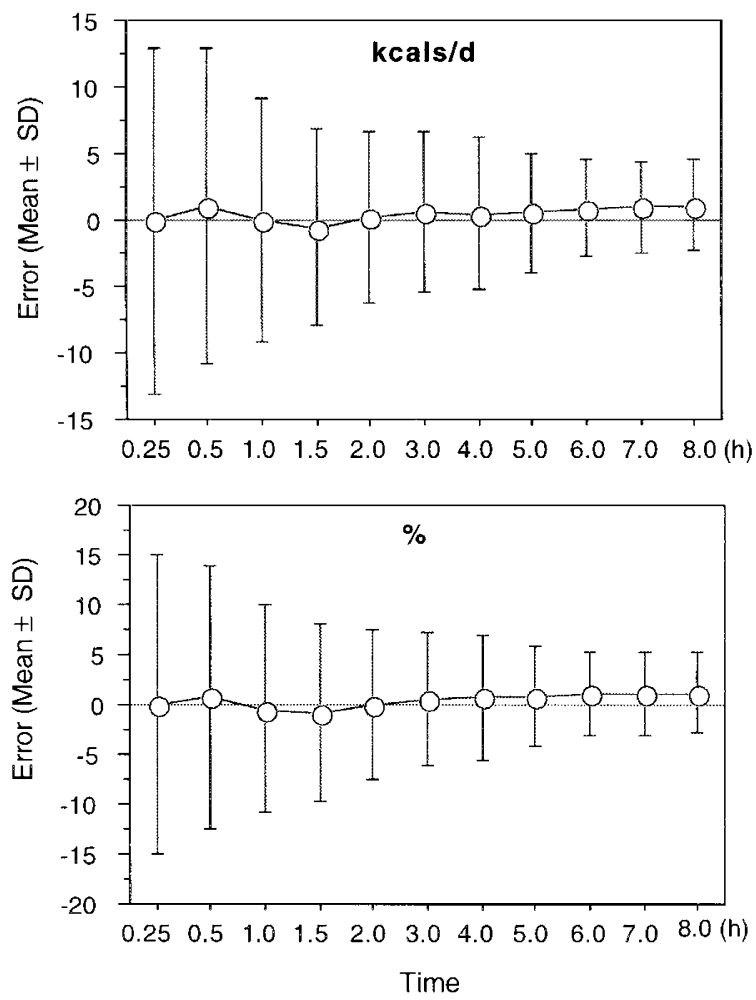

Figure 4. Error estimates in energy expenditure.

The within-day changes in EE are presented in Fig. 4. No significant differences were detected between accumulated 24-h EE and any of the other values. However, the SD of the
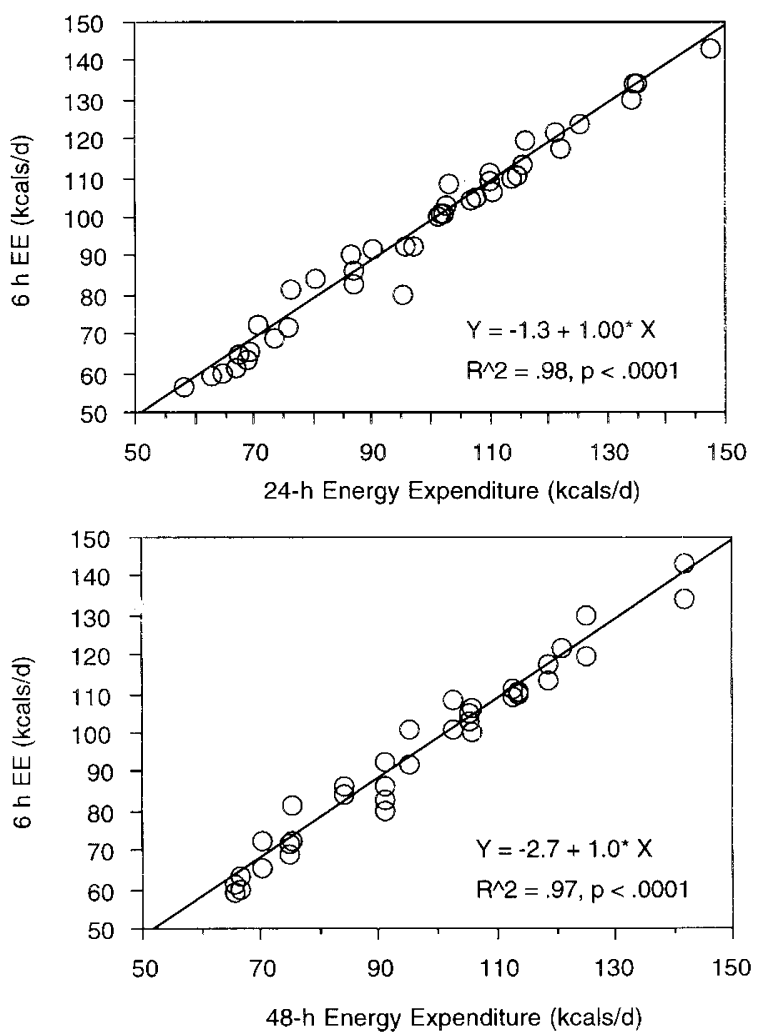

Figure 5. Relationship between 6- and 24-h and between 6- and 48-h energy expenditure determinations. Data were analyzed using simple regression analysis.

difference decreased between $0.25 \mathrm{~h}$ and $6 \mathrm{~h}$ but did not change thereafter. At $6 \mathrm{~h}$, mean $( \pm \mathrm{SD})$ absolute error was $0.9 \pm 3.8$ $\mathrm{kcal} / \mathrm{d}$ reflecting a fractional error of $1 \pm 4 \%$. The relationship between EE (kcal/d) at $6 \mathrm{~h}$ and $\mathrm{EE}$ at 24 and $48 \mathrm{~h}$ is also presented in Fig. 5; the intercepts did not differ from zero and the slopes were close to unity.

Data (mean $\pm \mathrm{SD}$ ) for the 2-wk study period are presented in Table 1. Body weight increased during the study with a mean gain of $56 \mathrm{~g} / \mathrm{d}$. In absolute terms (kcal/d), EI and EE did not increase between the two contiguous $24 \mathrm{~h}$ periods but did increase between week 1 and week 2. Stepwise regression analysis with $\mathrm{EE}$ as the dependent variable and EI, body weight, birth weight, gestational age, postnatal age, postconceptional age, and weight gain as the independent variables indicated that $\sim 85 \%$ of the variation in EE was related to EI, the other variables having no effect.

On a body weight basis, no differences were detected in EI or EE between the two contiguous $24 \mathrm{~h}$ periods or between the 2 weeks. Stepwise regression analysis indicated that $\sim 20 \%$ of the variation in EE was related to EI $(p<0.05)$, the other variables had no effect. Respiratory quotient did not change over the 2-week period.

After Fisher's adjustment for degrees of freedom the variance associated with biologic variability was $1577 \mathrm{kcal} / \mathrm{d}$ and the variance associated with dietary intake, body weight, age, and weight gain was $278 \mathrm{kcal} / \mathrm{d}$. The number of infant pairs required was about six times greater with the parallel than the cross-over design. 
Table 1. Energy intake and expenditure in the study infants

\begin{tabular}{|c|c|c|c|c|c|}
\hline \multirow[b]{2}{*}{ Period } & \multicolumn{2}{|c|}{ Week 1} & \multicolumn{2}{|c|}{ Week 2} & \\
\hline & $\mathrm{a}^{*}$ & $b^{*}$ & $\mathrm{c}^{*}$ & $d^{*}$ & \\
\hline \multicolumn{6}{|l|}{ Energy intake } \\
\hline $\mathrm{kcal} /$ day & $205 \pm 35$ & $219 \pm 38$ & $272 \pm 77$ & $276 \pm 63$ & $\mathrm{a}, \mathrm{b}<\mathrm{c}, \mathrm{d}(p<.005)$ \\
\hline $\mathrm{kcal} \cdot \mathrm{kg}^{-1} \cdot \mathrm{day}^{-1}$ & $122 \pm 10$ & $122 \pm 7$ & $130 \pm 20$ & $127 \pm 12$ & $p=\mathrm{NS}$ \\
\hline \multicolumn{6}{|l|}{ Energy expended } \\
\hline $\mathrm{kcal} /$ day & $84 \pm 21$ & $84 \pm 18$ & $108 \pm 21$ & $110 \pm 22$ & $\mathrm{a}, \mathrm{b}<\mathrm{c}, \mathrm{d}(p<.005)$ \\
\hline $\mathrm{kcal} \cdot \mathrm{kg}^{-1} \cdot \mathrm{day}^{-1}$ & $50 \pm 7$ & $48 \pm 5$ & $52 \pm 4$ & $51 \pm 5$ & $p=\mathrm{NS}$ \\
\hline RQ & $0.93 \pm 0.04$ & $0.95 \pm 0.06$ & $0.95 \pm 0.04$ & $0.95 \pm 0.03$ & \\
\hline
\end{tabular}

Values are means \pm SD.

* indicates each 24-h period.

\section{DISCUSSION}

The accuracy of IC in measuring EE has been questioned. Using an open canopy for gas sampling Bauer et al. (12) report a mean error of $-13 \pm 1$ and $-14 \pm 5 \%$ for $\mathrm{VO}_{2}$ and $\mathrm{VCO}_{2}$ measurements, while the error in $\mathrm{VO}_{2}$ measurements varied from $-2 \pm 5 \%$ to $-70 \pm 11 \%$ depending on body position of the manikin. In this study, the mean errors for $\mathrm{VCO}_{2}$ and $\mathrm{VO}_{2}$ determinations were $-1.0 \pm 6.1$ and $-0.9 \pm 5.8 \%$, and while the error also varied, it was somewhat less in conditions simulating an EB collection than when a standard mattress was used.

Previous studies suggest that 24-h EE can be estimated from a 6-h reading $(14,22)$. Data from this study suggests that $24-\mathrm{h}$ and 48-h EE can also be deduced from a 6-h determination. However, Bell et al. used a 30-min equilibration time followed by a fixed 90-min EE collection period (14). Actual EE measurements, therefore, were $4.5 \mathrm{~h}$ in duration rather than $6.0 \mathrm{~h}$. Surprisingly, the error in EE measurements in the study of Bell et al. and this study were quite similar, suggesting that either approach may be used. Shorter equilibration times coupled with variable EE collection periods may facilitate data collection in the clinical care setting.

Previous studies have shown that EE is affected by EI and factors such as body weight, size for gestation, age, method of feeding, behavioral state, and growth $(2,23-29)$. Because many of these factors co-exist they have been difficult to separate. To more closely examine the relative effects of these factors dietary intake and method of feeding were closely controlled during the study.

Despite the fact that EI and EE $(\mathrm{kcal} / \mathrm{kg} / \mathrm{d})$ did not change over the 2-wk period, EI remained an important determinant of EE. Interesting enough, the magnitude of effect appeared to differ depending on whether the data were expressed as $\mathrm{kcal} / \mathrm{d}$ (EI accounted for $\sim 85 \%$ of the variability in EE), or $\mathrm{kcal} / \mathrm{kg} / \mathrm{d}$ (EI accounted for $\sim 20 \%$ of the variation in EE). This apparent difference is puzzling but might be explained as follows.

During stepwise regression, a partial correlation coefficient $(\mathrm{R})$ is initially calculated between the dependent; e.g. EE, and each independent variable; e.g. EI, body weight, etc. (step 0). The independent variable with the most significant $R$ is entered into the regression equation. $\mathrm{R}$ is recalculated between the dependent and each remaining independent variable. The variable with the most significant $\mathrm{R}$ is then added to the equation and the process is repeated until no significant associations are noted. However, R reflects not only strength of association but also range of values.

In this study during step 0, the $\mathrm{R}$ value between EI and EE was 0.91 and the $\mathrm{R}$ value between body weight and $\mathrm{EE}$ was 0.90 , while the range of EI was $140-457 \mathrm{kcal} / \mathrm{d}(\sim 325 \%)$ and the range of body weight was $1230-2260 \mathrm{~g}(\sim 180 \%)$. Given the co-linear nature of EI and body weight, the greater range of EI may have masked effects due to body weight. Only when the data were analyzed on a weight basis were the effects due to body mass detectable.

The relative effects of biologic variability, age, weight, and weight gain, have important implications for the design and interpretation of energy balance studies in preterm infants. During energy balance a parallel or cross-over design may be used. However, variation due to biologic variability, confounds those associated with treatment and limit precision of the parallel design, while variation due to a "period" effect; i.e. dietary intake, weight, age, weight gain, limits the precision of the cross-over design.

In this study where dietary intake was closely controlled, the variance due to biologic variability was approximately six times greater than that of the other variables. This is consistent with the significant biologic variability also observed in term infants (30) and indicates that cross-over may be the preferred method study design during short-term studies of energy balance in these infants.

The findings of this study are important. The accuracy of the canopy as a method of gas sampling during IC has been questioned (12). Data from this study suggest that while the canopy tends to underestimate $\mathrm{VCO}_{2}$ and $\mathrm{VO}_{2}$, the error is small and should not limit use of IC for EE determinations during EB collections in preterm infants. Although EE is an integral part of $\mathrm{EB}$, no data are available on the length of time needed to obtain accurate and reproducible measures of $\mathrm{EE}$ referable to a 48-h EB collection. This is the first study to provide such data.

Controversy exists with regard to the means of expression of EE (31). Results of this study suggest that when EE expressed on an absolute may be misleading and supports the idea that EE be expressed on a body weight basis. Many factors affect EE which tend to coexist, are difficult to separate, and confound the interpretation of dietary intervention. In this study the effects of biologic variability were greater than those due to body weight, age, and weight gain suggesting that cross-over 
may be the preferred method of study design when examining the short-term effects of dietary intervention on EE in these infants. This is the first study to provide such data.

\section{REFERENCES}

1. Schulze KF, Stefanski M, Masterson J, Spinnazola R, Ramakrishnan R, Dell RB Heird WC 1987 Energy expenditure, energy balance, and composition of weight gain in low birth weight infants fed diets of different protein and energy content. J Pediatr 110:753-759

2. Catzeflis C, Schutz Y, Micheli JL, Welsch C, Arnaud MJ, Jequier E 1985 Whole body protein synthesis and energy expenditure in very low birth weight infants. Pediatr Res 19:679-687

3. Whyte RK, Haslam R, Vlainic C, Shannon S, Samulski K, Campbell D, Bayley HS, Sinclair JC 1983 Energy balance and nitrogen balance in growing low birthweight infants fed human milk or formula. Pediatr Res 17:891-898

4. Reichman BL, Chessex P, Putet G, Verellen GJ, Smith JM, Heim T, Swyer PR 1982 Partition of energy metabolism and energy cost of growth in the very low-birthweight infant. Pediatrics 69:446-451

5. Putet G, Senterre J, Rigo J, Salle B 1984 Nutrient balance, energy utilization, and composition of weight gain in very-low-birth-weight infants fed pooled human milk or a preterm formula. J Pediatr 105:79-85

6. Putet G, Senterre J, Rigo J, Salle B 1987 Energy balance and composition of body weight. Biol Neonate 52(suppl 1):17-24

7. Whyte RK, Campbell D, Stanhope R, Bayley HS, Sinclair JC 1986 Energy balance in low birth weight infants fed formula of high or low medium-chain triglyceride content. J Pediatr 108:964-971

8. Kashyap S, Schulze KF, Forsyth M, Dell RB, Ramakrishnan R, Heird WC 1990 Growth, nutrient retention, and metabolic response of low-birth- weight infants fed supplemented and unsupplemented preterm human milk. Am J Clin Nutr 52:254-262

9. Roberts SB, Murgatroyd PR, Crisp JA 1987 Long-term variation in oxygen consumption rate in preterm infants. Biol Neonate 52:1-8

10. Freymond D, Schutz Y, Decombaz J, Micheli JL, Jequier E 1986 Energy balance, physical activity, and thermogenic effect of feeding in premature infants. Pediatr Res 20:638-645

11. Picaud JC, Putet G, Rigo J, Salle BL, Senterre J 1994 Metabolic and energy balance in small- and appropriate-for- gestational-age, very low-birth-weight infants. Acta Paediatr Suppl 405:54-59

12. Bauer K, Pasel K, Uhrig C, Sperling P, Versmold H 1997 Comparison of face mask, head hood, and canopy for breath sampling in flow-through indirect calorimetry to measure oxygen consumption and carbon dioxide production of preterm infants $<$ 1500 g. Pediatr Res 41:139-144

13. Stothers JK 1981 Head insulation and heat loss in the newborn. Arch Dis Child $56: 530-534$
14. Bell EF, Rios GR, Wilmoth PK 1986 Estimation of 24-h energy expenditure from shorter measurement periods in premature infants. Pediatr Res 20:646-649

15. Moon JK, Jensen CL, Butte NF 1993 Fast-response whole body indirect calorimeters for infants. J Appl Physiol 74:476-484

16. Schulze K, Kairam R, Stefanski M, Sciacca R, Bateman D, Dell R, James LS 1981 Spontaneous variability in minute ventilation oxygen consumption and heart rate of low birth weight infants. Pediatr Res 15:1111-1116

17. Marks KH, Coen P, Kerrigan JR, Francalancia NA, Nardis EE, Snider MT 1987 The accuracy and precision of an open-circuit system to measure oxygen consumption and carbon dioxide production in neonates. Pediatr Res 21:58-65

18. Takala J, Keinanen O, Vaisanen P, Kari A 1989 Measurement of gas exchange in intensive care: laboratory and clinical validation of a new device. Crit Care Med 17:1041-1047

19. Takala J, Merilainen P 1994 Handbook of Gas Exchange and Indirect Calorimetry. Datex Division of Instrumentation Corporation, Helsinki

20. McLean J, Tobin G 1987 Animal and Human Calorimetry. Cambridge University Press, Cambridge

21. Snedicor G, Cochrane W 1980 Statistical Methods. Iowa State University Press, Ames, pp 83-106

22. Schulze K, Stefanski M, Masterson J, Kashyap S, Sanocka U, Forsyth M, Ramakrishnan R, Dell R 1986 An analysis of the variability in estimates of bioenergetic variables in preterm infants. Pediatr Res 20:422-427

23. Brooke OG, Wood C, Barley J 1982 Energy balance, nitrogen balance, and growth in preterm infants fed expressed breast milk, a premature infant formula, and two low-solute adapted formulae. Arch Dis Child 57:898-904

24. Brooke OG 1985 Energy expenditure in the fetus and neonates: sources of variability. Acta Paediatr Scand 74:128-134

25. Chessex P, Reichman B, Verellen G, Putet G, Smith JM, Heim T, Swyer PR 1984 Metabolic consequences of intrauterine growth retardation in very low birthweight infants. Pediatr Res 18:709-713

26. Cauderay M, Schutz Y, Micheli JL Calame A, Jequier E 1988 Energy-nitrogen balances and protein turnover in small and appropriate for gestational age low birthweight infants. Eur J Clin Nutr 42:125-136

27. Gudinchet F, Schutz Y, Micheli JL, Micheli JL, Stettler E, Jequier E 1982 Metabolic cost of growth in very low-birth-weight infants. Pediatr Res 16:1025-1030

28. Sauer PJJ, Dane HJ, Visser HKA 1984 Longitudinal studies on metabolic rate, heat loss, and energy cost of growth in low birth weight infants. Pediatr Res 18:254-259

29. Butte NF, Jensen CL, Moon JK, Glaze DG, Frost JD Jr 1992 Sleep organization and energy expenditure of breast-fed and formula-fed infants. Pediatr Res 32:514-519

30. Denne SC, Kalhan SC 1986 Glucose carbon recycling and oxidation in human newborns. Am J Physiol 251:E71-E77

31. Denne S 1998 Energy requirements. In: Polin R, Fox W (eds) Fetal and Neonatal Physiology. WB Saunders Company, Philadelphia, pp 307-314 